\title{
Euthanasia forEnd Stage Cancer Patients: A Right to Die? A Policy Brief
}

\author{
Mahmoud K. Al Hamarsheh ${ }^{1}$, Majd T. Mrayyan², \\ ${ }^{I} M S N c$, RN, Oncology Nursing Master's Student, Faculty of Nursing, The Hashemite University, Jordan \\ mahmoud.alhamarsheh@gmail.com \\ ${ }^{2} P h D, R N$, Professor, Consultant of Nursing, Dean of Scientific Research, The Hashemite University, Jordan \\ mmrayyan@hu.edu.jo
}

\begin{abstract}
Euthanasia is a worldwide controversial issue which has different perceptions and policies in the medical field around the globe. A change has to be made to provide alternatives for those patients who are suffering from terminal cancer, such as palliative care. This policy brief provides a discussion and recommendation regarding end stage cancer patient's euthanasia alternatives, and it is directed to the Jordanian Medical Council (JMC) via the Higher Education Faculty in the Hashemite University. Giving that the policy of euthanasia is not available in Jordan because it is prohibited by the law, the focus on palliation services and care requires a great amount of attention. Both of the patients and families deserve to be aware of palliative care options available. In conclusion, the researcher presented the Jordanian Medical Council (JMC) with several recommendations for the improvement of euthanasia policy related to end stage cancer patients. Andthe researcher would be pleased to discuss these recommendations with the Jordanian Medical Council $(J M C)$, or to provide expanded information at request.
\end{abstract}

Keywords: assisted dying,cancer patients, euthanasia, palliative care

\section{Executive Summary}

\section{Introduction}

A policy brief is a short document that presents the findings and recommendations of aresearch project to a non-specialized audience (International Development Research Centre[IDRC], 2016). Euthanasia is a concept describing the process of ending a life of a person by another to avoid upsetting effects of an illness (Kennedy and Grubb, 1998). An end stage cancer patient is a patient diagnosed with stage IV terminal cancer and expected to be fatal within a year. Euthanasia is a worldwide controversial issue which has different perceptions and policies in the medical field around the globe. Whose role to decide if a patient has or has not the right to die? and should cancer patients be given the right to end their lives peacefully? Till now, in Jordan we still don't have a policy regarding euthanasia because it is forbidden by the law according to The Medical Jordanian Constitution (1989, art $1, \S 3$ ) "You may not end the lives of patients with incurable disease is whatever accompanied by pain, whether its direct or indirect intervention except for brain death which shall be approved by the union in accordance to scientific terms". A change has to be made to provide alternatives for those patients who are suffering from terminal cancer, such as palliative care.This policy brief provides a discussion and recommendation regarding end stage cancer patient's euthanasia alternatives, and it is directed to the Jordanian Medical Council (JMC) via the Higher Education Faculty in the Hashemite University.

\section{Context\& Importance of the Problem}

Thousands of patients around the world have a legal right to end their lives in a peaceful way, but what happens if they were denied this right? As a part of the medical professions in Jordan nurses need to be incorporated into the authority of making an alternative, such one is palliation service and counselling.Nurses' attitudes toward euthanasia differ from to another according to legal regulations, the professional code of ethics, professional experience, personal value systems, religion, and age (Verpoort et al, 2004). They are the people who spend most of the time with dying patients and their relatives. Therefore, they carry an emotional burden as they care for their patients.

\section{Active Euthanasia}

The ethical and legal aspects of the concept of euthanasia are still widely debated in many countries of theworld.Active euthanasia is a process where the death of a person results from a specific act directed at causing their death(Griffith, 2014).According to the US National Right to Life Committee (2009),euthanasia can be voluntary (requested by the person), non-voluntary (the person who is killed made no request and gave no consent) or involuntary(the person who is killed made an expressed wish to the contrary). A general overview of euthanasia laws around the world is presented in (Fig. A) 


\section{Religious Views on Euthanasia}

It's still hard in Jordan to legalise such an issue because its forbidden by both the Holy Quran and The Bible. "Believers, do not consume your wealth among yourselves in falsehood, except there be trading by your mutual agreement. And do not kill yourselves. Allah is the Most Merciful to you" (Quran 4: 28-29). On the other hand, the Bible also described it in the Tenth amendment "Thou shalt not kill' 'Also in Muslim countries, it is contrary to euthanasia to become a legally sanctioned act, such an act would usually be regarded as contrary to Islamic jurisprudence (Aramesh \& Shadi, 2007).In Jordan, euthanasia is illegal even if informed consent is taken from the patient or his family, thus it is considered a crime against human life and the one who commits euthanasia whether actively or passively will be punished by the law as being an intentional act, (Naga\&Mrayyan, 2013).

\section{Policy Implications and Relevance}

Currently,while most of incurable diseases are being treated, many diseases, such as cancer, which impose pain and suffering upon the patients are still common. The places of care (e.g. hospital, hospice, home), and the connection between ethical and clinical considerations are among the main issues that cancer care faces nowadays (Mousavi,Akbari, Kashani, Akbari, \& Sepas, 2011).The Jordanian patients who suffer from a terminal stage cancer need a great amount of relief, some may find it in comforting and pain killers, others may find it in ending his life peacefully and in dignity. Giving that the policy of euthanasia is not available in Jordan due to the prohibition of law, the focus on palliation services and care requires a great amount of attention. Both of the patients and families deserve to be aware of palliative care options available.

\section{Critique of Policy Options}

The option for palliative care is highly necessary, and its mandatory that most end stage cancer patients will need getting them to the time they are aided to die in peace. The main problem in Jordan regarding palliation services that there is only one center that delivers palliative care in universal standards which is King Hussein Cancer Center (KHCC), and besides that not all cancer patients have to chance for admission due to logistic issues, financial issues, or the lack of vacancies in the center.

\section{Euthanasia as An Option}

Even when we legalize euthanasia it might not be as feasible as we might think in Jordan due to several factors. Family and culture will not tolerate this law easily and many concerns will emerge regarding vulnerable patients (low income, low level of education, and patients with disabilities), also not all health care providers will consider participating in euthanasia due to religious or spiritual beliefs. Some fear that the use of euthanasia will decrease the use of palliative care services, services that could improve patients' quality of life and reduce the need for euthanasia (Tilden, Tolle, Lee,\& Nelson, 1996).

\section{Palliative Care}

Palliative care services do not have the full capacity to care for all dying patients and it is arrogant to suggest this is the whole answer (Maher, 2012). Each cancer patient should have the right to free, accessible and truthful information on the end-of life choices, and to be able to make informed decisions about how they choose to end their lives.The World Health Organization(WHO) recommends that governments devote more attention to pain relief and palliative care before considering laws to allow euthanasia. Most patients who request euthanasia change their minds once satisfactory pain control is established(WHO, 1990).

\section{Policy Recommendations}

In conclusion, the researchers would like to present the Jordanian Medical Council (JMC) the following recommendations for the improvement of euthanasia policy related to end stage cancer patients:

\section{Raise the Number of Facilities Providing Palliative Care}

Giving that there is only one centre (KHCC) that provides palliative care for cancer patients this will cause overload and decrease the percentage of patients that receive palliative services. On the other hand, increasing the number of these facilities will cover much numbers of patients who are in need for comforting care and pain management. Also, we need to distribute these facilities over numerous geographical cities to serve larger numbers of cancer patients in all of Jordan.

\section{Provide High Quality Palliative Services}

Having a high quality palliative care will definitely eradicate the patient's need for active or passive euthanasia, and there have been advancements in the palliative field in the recent years that support this point of view.

\section{Promote Trust between Health Care Providers and Patients}

Nurses are part of the health care system and one of the most health care providers that spend much time with their dying patients, if they can build a trust relationship with patient and his family they will be able 
to affect their decisions in choosing the best way to end his life in a dignified way, pushing him farther away from the euthanasia option, and towards other options available.

\section{Reinforce Religious Faith and Beliefs}

Islam is the faith of the majority of Jordanian population, and considering euthanasia to be forbidden in our religion, the patient, the family, and society will realize that the laws of Allah will be compromised. So, we need to strengthen the relationship between the patient and his god in order to respect the sanctity of the human life and soul. This can be achieved by advising him to read The Quran more often, and keeping his prayers at all times.

\section{Initiate Counselling Services}

A social or spiritual counsellor need to be available at every facility providing care for patients with cancer. This counsellor must provide suggestions and alternatives for dignified dying and he must be well educated in the field of palliative care, and has a great communication skills with vulnerable patients, because lots of them are assisted to die against their will most of the time.

\section{Training and Education for Providers}

Professional and medical organizations should participate in educational programs, health care providers such as nurses would also benefit from continued education on discussing end-of-life concerns. Such training could increase provider's comfort and capability in conferring euthanasia and palliative care.

Finally, the researchers would like to emphasize on the importance of end of life palliative care, and the possible methods that a patient with end stage cancer may choose to end his life. Euthanasia is still debatable around the world and much more attention should be considered before approving such a policy that allows ending life deliberately. The researchers would be pleased to discuss these recommendations with the Jordanian Medical Council (JMC), or to provide expanded information at the council's request.

\section{Acknowledgements}

The researcherwishes to acknowledge Prof Majd Mrayyan, $\mathrm{PhD}, \mathrm{RN}$, for her support in reviewing and editing of this Policy Brief paper.

\section{References}

[1]. IDRC - International Development Research Centre. (n.d.). Retrieved December 13, 2016, from https://www.idrc.ca/en

[2]. Kennedy, I, Grubb A (1998) Principles of Medical Law. Oxford University Press, Oxford.

[3]. The Medical Jordanian Constitution, M.J.C. § Article three (1989).

[4]. Verpoort C, Gastmans C, De Bal N, Dierckx de Casterlé B (2004) Nurses' attitudes to euthanasia: a review of the literature. Nurs Ethics 11(4): 349-65.

[5]. Griffith, R. (2014). Should assisted dying be lawful? British Journal of Community Nursing, 19(2), 94-98. doi:10.12968/bjen.2014.19.2.94

[6]. National Right to Life Committee (2009) Euthanasia, www.nrlc.org/euthanasia/ (accessed 10 November 2016).

[7]. International Perspectives on Euthanasia. (n.d.). Retrieved November 15, 2016, from http://sites.psu. edu/mehealth/2015/ 04/06/international-perspectives-on-euthanasia/

[8]. The Holy Quran, Translation by Shakir MH, Publisher c/o No. 95 Chatsworth Road, London, 1983.

[9]. Aramesh, K. \& Shadi, H. (2007) Euthanasia: an Islamic ethical perspective. Iranian Journal of Allergy, Asthma, and Immunology, 6 (Suppl. 5), 35-38.

[10]. Naga, B. S., \& Maryyan, M. T. (2013). Legal and Ethical Issues of Euthanasia: Argumentative Essay. Middle East Journal of Nursing MEJN, 7(5), 31-39. doi:10.5742/mejn.2013.75330

[11]. Mousavi S., Akbari A., Kashani F., Akbari M., \& Sepas H. (2011). Euthanasia in Cancer Patients, Islamic Point of View. Iranian Journal of Cancer Prevention, 4(2), 78-81.

[12]. Tilden VP, Tolle SW, Lee MA, Nelson CA. 1996. Oregon's Physician-Assisted Suicide Vote: Its Effect on Palliative Care. Nursing Outlook 44(2):80-83.

[13]. Maher, J.A. (2012) Nursing voice needed in end-of-life choice bill debate. Kai Tiaki Nursing New Zealand; 18: 9, p30.

[14]. World Health Organization. (1990). Cancer pain relief and palliative care: Report of a WHO Expert Committee [Technical Report Series 804]. Geneva, Switzerland. 


\section{Appendices}

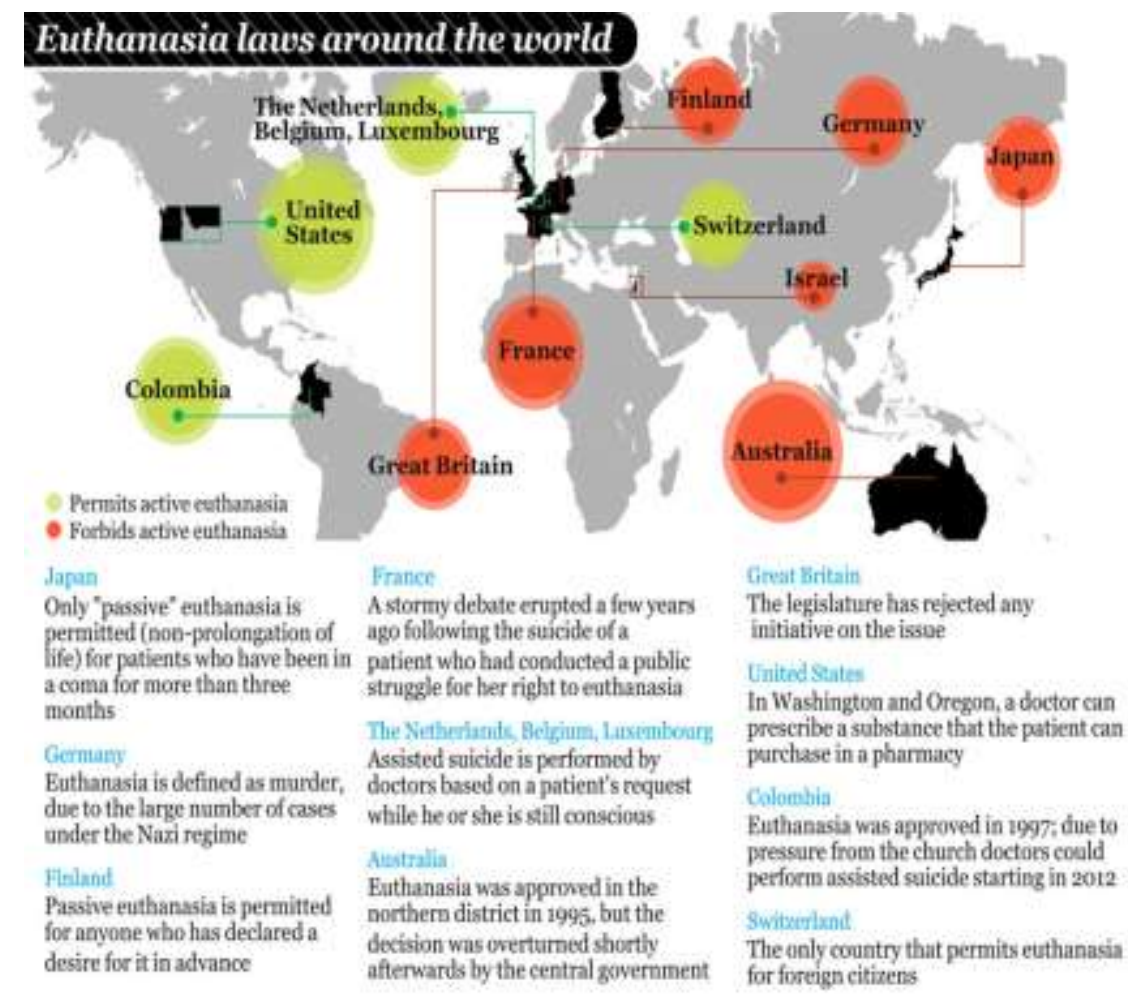

Figure (A)

(international perspectives on euthanasia) 